\title{
Effect of cholecystectomy on hepatic fat accumulation and insulin resistance in non- obese Hispanic patients: a pilot study
}

\author{
Víctor Cortés ${ }^{1,2}$, Nicolás Quezada ${ }^{3}$, Sergio Uribe ${ }^{4}$, Marco Arrese ${ }^{1,5}$ and Flavio Nervi ${ }^{1 *}$
}

\begin{abstract}
Background: Nonalcoholic fatty liver disease (NAFLD) is highly prevalent worldwide. Experimental studies have shown that cholecystectomy (XGB) increases hepatic fat content in mice and appears associated to NAFLD in large retrospective population-based studies. The aim of this study was to prospectively assess the effects of XGB on hepatic fat content (HFC) and insulin resistance (IR) in non-obese, middle aged Hispanic subjects.

Methods: Twenty-six gallstone patients undergoing elective XGB and 16 control subjects with normal livers and gallbladders at ultrasonography were prospectively followed 24 months for changes in HFC and IR. Clinical, biochemical determinations and hepatic imaging were performed at baseline and 24 months after surgery. MRI technique quantified HFC in four hepatic segments. IR was assessed by the Homeostasis Model Assessment $\left(\mathrm{HOMA}_{-1 \mathrm{R}}\right)$ index.
\end{abstract}

Results: Initial body mass index (BMI) was $25.6 \pm 0.4$ and $24.3 \pm 1.0$ in the control and XGB groups of subjects, respectively. Serum insulin level increased from $8.1 \pm 0.7$ to $10.0 \pm 1.9(\mu \mathrm{U} / \mathrm{ml}) 24$ months after surgery in XGB patients $(p<0.05)$; no significant changes were detected in control individuals. Median HOMA $\mathrm{IR}_{\mathrm{R}}$ index increased from 1.31 (interquartile range, 1.01-1.68) to 2.20 (interquartile range, 1.57 - 2.60) 24 months after $X G B,(p<0.003)$. Median $H_{O M A}$ index of control subjects remained unchanged at the end of the study. Serum apoB concentration increased from 61. $5 \pm 3.4$ to $79.0 \pm 7.8(\mu \mathrm{g} / \mathrm{ml})$ in XGB patients $(p<0.03)$. Serum apoB levels remained within normal ranges in both periods of the study in control subjects. HFC significantly increased in 2 of the 4 segments 24 months after XGB: right posterior hepatic lobe (from $5.3 \pm 0.2 \%$ to $6.0 \pm 0.2 \%, p>0.04$ ) and right anterior hepatic lobe (from $5.8 \pm 0.2 \%$ to 6 . $6 \pm 0.3 \%, p<0.02)$. The average HFC of the four hepatic segments studied slightly increased from $5.4 \pm 0.2$ to $5.8 \pm 0.3$ 2 years after XGB $(p<0.03)$. No significant changes were found in HFC in the control subjects at the end of the study.

Conclusions: Elective XGB increases HFC, HOMA $\mathrm{AR}_{\mathrm{R}}$ index and serum apoB concentration. These results support the notion that XGB is a risk factor non-alcoholic fatty liver disease and other IR - associated disease conditions.

Keywords: Gallbladder, Cholecystectomy, Steatosis, NAFLD, Insulin resistance

\section{Background}

Nonalcoholic fatty liver disease (NAFLD) is highly prevalent worldwide with an estimated rate of $30 \%$ among the adult population diagnosed by abdominal ultrasound [1-3]. South American and Mexican American Hispanics have the highest prevalence rates of NAFLD with figures ranging between 30 to $50 \%$ of the population [4]. NAFLD is

\footnotetext{
* Correspondence: fnervi@med.puc.cl

'Departamento de Gastroenterología, Facultad de Medicina, Pontificia

Universidad Católica de Chile, 6513677 Santiago, Chile

Full list of author information is available at the end of the article
}

frequently associated to obesity, type 2 diabetes, atherosclerosis and cholesterol gallstones [5-7] with these entities sharing some metabolic alterations. NAFLD has a complex bidirectional pathogenic interrelationship with the metabolic syndrome (MS). NAFLD is considered both, a metabolic manifestation of MS and in some cases, a primary determinant of insulin resistance (IR) and the metabolic abnormalities clustered in the MS [8-12]. The natural history and possible evolution of NAFLD varies greatly in seriousness, starting as an accumulation of fat in the hepatocyte and potentially evolving towards nonalcoholic 
steatohepatitis (NASH), cirrhosis and hepatocellular carcinoma [13-15].

The cause of the increase of triglycerides (TG) in NAFLD has not been completely unveiled. However, it is known that IR is a fundamental pathogenic factor that alter each of the processes that regulate TG concentration in the liver by increasing hepatic lipogenesis and lipolysis from adipocytes, and decreasing peripheral lipoprotein lipase activity, producing an increase of chylomicron and VLDL remnants, which are rapidly cleared by the liver, thus resulting in a net TG accumulation in the organ [16-18].

Cholecystectomy (XGB) is the recommended treatment for gallbladder (GB) diseases, including gallstone disease (GSD) and cholecystitis [19]. Indeed, XGB is one of the most commonly performed surgical procedures worldwide $[20,21]$ and is considered a low-risk surgical procedure with no major long-term health implications. However, recent evidence shows that the GB may not only be a simple reservoir that stores, concentrates and delivers bile into the intestine for lipid absorption. Through its critical role in regulating bile acid (BA) metabolism and the recent finding that GB mucosa is rich in the hormone Fibroblast Growth Factor 19 (FGF19), this organ may have a physiological role in whole body metabolic homeostasis [22, 23]. In fact, the possibility that GB ablation may have metabolic consequences has emerged [24] due to recent retrospective epidemiological studies showing that XGB may be a risk factor of NAFLD) $[25,26]$ and metabolic syndrome [27]. Concordantly, experimental studies in mice have shown that XGB increases basal metabolic rate, serum and hepatic triglycerides concentration and very low-density lipoprotein (VLDL) production [28, 29]. Moreover, XGB has been associated with elevated VLDL levels [30], deteriorated postprandial glycemic control [31] and weight gain [32] in humans. The underlying mechanisms of these effects remain ill defined. Since BAs are important signaling molecules in controlling lipid and carbohydrate metabolism [33-35] it is plausible that XGB may influence whole-body metabolic regulation through changes in BA physiology and potentially contributing to the development of IR and MS - associated conditions, particularly NAFLD [19-21].

To better define the potential role of XGB as a risk factor of NAFLD, the present study aimed to prospectively evaluate the effects of XGB on liver fat content and IR, one of the most relevant factors underlying NAFLD development [36]. To that end, we determined IR by the homeostatic model assessment index (HOMA-IR) [37] and hepatic fat by magnetic resonance imaging (MRI) $[38,39]$ in a series of non-obese GSD patients over a period of 24 months after elective XGB.

\section{Methods}

\section{Patient selection}

This study agreed with the ethical guidelines of Declaration of Helsinki (1975) and was approved by the Institutional Review Board for Human Studies of the Faculty of Medicine at Pontificia Universidad Católica de Chile. All participants gave informed written consent prior to participate in this survey.

We arbitrarily included 30 patients harboring asymptomatic gallstone disease subjected to elective laparoscopic XGB at the Clinical Hospital of the Pontificia Universidad Católica de Chile, between January and August 2013. We also studied a group of 20 control subjects with similar clinical and biochemical characteristics and normal GBs at abdominal ultrasound. Twenty-six cholecystectomized patients and 16 control subjects completed the study 24 months later.

All subjects were 35 to 55 years old, non-diabetic and non-obese who agreed to participate in the study. Inclusion criteria were: a) body mass index (BMI) $<28$ and no change in weight of more than $3 \mathrm{~kg}$ in the last 6 months before entering the study; b) fasting glucose, lipid levels and liver function tests within normal values; c) absence of hepatic steatosis assessed by abdominal ultrasound; d) no use of glucose- and lipidlowering drugs, estrogens or androgens. Exclusion criteria were: a) abnormal serum alanine aminotransferase (ALT) or aspartate aminotransferase (AST) concentrations; b) hepatic pathologies on MRI; c) alcohol consumption $>20$ g per day in the last 3 years; e) substance abuse; $f$ ) significant systemic diseases and g) inability to undergo MRI.

\section{Clinical and biochemical assessments}

Baseline clinical evaluation included medical history, physical exam, and height and weight measurements to calculate body mass index (BMI). Venous blood samples were obtained after $12 \mathrm{~h}$ of fasting. Glucose, lipids, insulin, apolipoprotein B (apoB), ALT and AST serum levels were measured at the central laboratory of Pontificia Universidad Católica de Chile Health Network. We used the homeostasis model assessment index $\left(\right.$ HOMA $\left._{- \text {IR }}\right)$ to define IR at fasting [20, 24]. We defined IR for non-obese middle-aged subjects when HOMA $_{\text {-IR }}$ values were $\geq 2.53$ according to a population -based Chilean study [40].

\section{Magnetic resonance imaging protocol and imaging analysis}

A magnetic resonance imaging (MRI) scanner $(1.5 \mathrm{~T}$ Philips Achieva MRI scanner, Best, The Netherlands) was used to quantitate hepatic fat content (HFC) A fat fraction map of the liver was generated based on IDEAL method [41]. Briefly, echo times were set to $\mathrm{TE}=2.3 \mathrm{/}$ 
3.5/ $4.7 \mathrm{~ms}$, corresponding to the optimal echo times in IDEAL algorithm for $1.5 \mathrm{~T}$ [42]. TRs and flip angles were chosen experimentally using fat-water-emulsion phantoms [43].

MRI data was processed with OSIRIX software (OsiriX Foundation, Geneva, Switzerland) to extract water and fat images. Afterwards, fat fraction map was extracted using image calculator tool of Image J software (NIH, Bethesda, MA, USA). In the fat fraction map, one region of interest (ROI) was set in four segments of the liver avoiding vascular structures. Four segment of the liver were analyzed: right posterior hepatic lobe (RPHL), anterior hepatic lobe (RAHL), left medium hepatic lobe (LMHL) and left lower hepatic lobe (LLHL). Mean FF was calculated for each ROI. Additionally, a mean value of the fat fraction of the liver was calculated by averaging the fat fraction values of the four ROI.

\section{Statistical analysis}

Parametric data were presented as mean $\pm \mathrm{SE}$ of the mean and non-parametric data were expressed as medians with interquartile values. Student's $t$ test was used to compare parametric data. Wilcoxon test was used for nonparametric variables and paired Chi-square tests were used to compare frequencies. Prism software (Version 6, http:// www.graphpad.com/) was used for statistical analysis. Differences were considered significant with $P$ values $<0.05$.

\section{Results}

Table 1 show that age and sex distribution was similar in XGB patients and control subjects. Importantly, BMI was in the upper limit of the normal range in both groups at the beginning and end of the study. Fasting serum glucose, insulin, lipids and apoB were also equivalent and within the normal range at the beginning of the study (Table 1). Twenty-four months after XGB, serum apoB levels of control individuals remained within normal ranges at end of the study $(68.1 \pm 3.4 \mathrm{vs} 63.1 \pm 2.8(\mu \mathrm{g} / \mathrm{ml})$, respectively). Serum apoB concentration of cholecystectomized patients increased from $61.5 \pm 3.4$ to $79.0 \pm 7.8(\mu \mathrm{g} / \mathrm{ml})$ in cholecystectomized patients $(p<0.03)$.

\section{XGB is associated with elevated serum insulin concentration and $\mathrm{HOMA}_{-\mathrm{IR}}$ index}

Serum insulin level increased from $8.1 \pm 0.7$ to $10.0 \pm 1.9(\mu \mathrm{U} / \mathrm{ml}) 24$ month after surgery in XGB patients $(p<0.05)$, whereas no significant changes were detected in control individuals (Table 1). As shown in Fig. 1, median HOMA $_{\text {-IR }}$ index of control subjects remained unchanged, from 1.42 (interquartile range, $1.02-1.86$ ) to 1.74 (interquartile range, 1.11 2.39) during the observational period. Contrariwise, median HOMA $_{-I R}$ index increased from 1.31 (interquartile range, 1.01-1.68) to 2.20 (interquartile range, 1.57 - 2.60) 24 months after XGB, $(p<0.003)$.We operationally defined IR when HOMA $_{\text {-IR }}$ was $\geq 2.53$ for middle-age, non-obese Chilean subjects [24]. Upon this definition, $15 \%$ of individuals in both groups had IR at the beginning of the study. Twenty-four months later, $61 \%$ of the patients subjected to XGB had HOMA $_{\text {IR }} \geq 2.53$, compared with only $12 \%$ in the control group of individuals $(p<0.001)$. Considered

Table 1 Age, weight, Body Mass Index (BMI), and biochemical parameters of the control and cholecystectomized individuals, at the beginning and end of the study

\begin{tabular}{|c|c|c|c|c|}
\hline \multirow{2}{*}{$\begin{array}{l}\text { Characteristic } \\
\text { Time (months) }\end{array}$} & \multicolumn{2}{|c|}{ Control $(N=16)$} & \multicolumn{2}{|c|}{ Cholecystectomy $(N=26)$} \\
\hline & 0 & 24 & 0 & 24 \\
\hline Age & $38.2 \pm 2.6$ & & $37.3 \pm 1.7$ & \\
\hline Female/male & $10 \mathrm{~F} / 6 \mathrm{M}$ & & $18 \mathrm{~F} / 8 \mathrm{M}$ & \\
\hline Body weight (kg) & $71.5 \pm 3.0$ & $72.0 \pm 3.2$ & $67.4 \pm 1.8$ & $71.5 \pm 2.3$ \\
\hline $\mathrm{BMI}\left(\mathrm{kg} / \mathrm{m}^{2}\right)$ & $25.6 \pm 0.4$ & $26.5 \pm 0.5$ & $24.3 \pm 1.0$ & $24.4 \pm 1.1$ \\
\hline $\mathrm{ALT}(\mathrm{U} / \mathrm{L})$ & $23.5 \pm 3.2$ & $27.9 \pm 4.7$ & $23.5 \pm 3.2$ & $27.9 \pm 4.7$ \\
\hline AST $(U / L)$ & $23.5 \pm 7.1$ & $11.6 \pm 7.7$ & $21.4 \pm 3.7$ & $22.7 \pm 3.1$ \\
\hline Serum glucose (mg/dl) & $85 \pm 1.5$ & $84 \pm 1.6$ & $79 \pm 1.6$ & $81 \pm 1.5$ \\
\hline Serum insulin $(\mu \mathrm{U} / \mathrm{ml})$ & $8.5 \pm 1.7$ & $9.4 \pm 1.3$ & $8.1 \pm 0.7$ & $10.0 \pm 1.9^{*}$ \\
\hline Total cholesterol (mg/dl) & $179 \pm 8$ & $182 \pm 7$ & $172 \pm 6$ & $197 \pm 8$ \\
\hline LDL cholesterol (mg/dl) & $105 \pm 7$ & $110 \pm 8$ & $100 \pm 6$ & $117 \pm 7$ \\
\hline HDL cholesterol (mg/dl) & $50 \pm 3$ & $49 \pm 3$ & $48 \pm 2$ & $55 \pm 2$ \\
\hline Triglycerides (mg/dl) & $118 \pm 12$ & $117 \pm 11$ & $121 \pm 10$ & $127 \pm 12$ \\
\hline Serum apoB $(\mu \mathrm{g} / \mathrm{ml})$ & $68.1 \pm 3.4$ & $63.1 \pm 2.8$ & $61.5 \pm 3.4$ & $79.0 \pm 7.0^{\#}$ \\
\hline
\end{tabular}

Plus minus values are means $\pm \mathrm{SE}, B M I$ body mass index, $A S T$ aspartate aminotransferase, $A L T$ alanine aminotransferase, $L D L$ low density lipoprotein, $H D L$ high density lipoprotein, $a p o B$ apoprotein B. ${ }^{*} p<0.05, " ~ p<0.03$ 




Fig. 1 Effect of $X G B$ on $H_{O M A}$ index. Values represent the median and the interquartile ranges. White columns represent results at the beginning of the study and columns with grey dots represent results obtained at the end of the study. ${ }^{*} P<0.02$; $P<0.001$

together, these results suggest that XGB determines increased circulating insulin levels and favors IR in non-obese individuals.

\section{XGB is associated with higher hepatic fat}

At the beginning of the study, all individuals of both groups had hepatic fat (HFC) lower than $8 \%$ as assessed by MRI, indicating that they had no, or mild steatosis [21,22]. Twenty-five cholecystectomized patients and 15 control subjects had a second MRI after 24 months of follow-up. Figure 2 shows that HFC of the four segments studied remained unchanged after 24 months of follow up in the control group. Contrariwise, patients subjected to XGB significantly increased HFC in the right posterior hepatic lobe (RPHL) $(5.3 \pm 0.2 \%$ to $6.0 \pm 0.2 \%, p>0.04)$ and in the right anterior hepatic lobe (RAHL) $(5.8 \pm 0.2 \%$ to $6.6 \pm 0.3 \%, p<0.02)$. The average value of HFC of the 4 hepatic segments, slightly increased $7 \%$, from $5.4 \pm 0.2 \%$ to $5.8 \pm 0.20 \%(P<0.05)$ in cholecystectomized patients. No significant change was found in the control group.

\section{Discussion}

This prospective pilot study shows that XGB is associated with a significant increase in HFC, serum apoB and insulin levels, as well as in HOMA -IR $_{\text {index, in a cohort }}$ of non-obese Hispanic subjects. These findings provide support to the contention that, whereas XGB cures GSD and eliminates the risk of $\mathrm{GB}$ cancer, it may have relevant negative metabolic consequences [22, 24], contributing to the development, or worsening of IR and its consequences. Of note, IR is a major pathophysiological determinant of type 2 diabetes, atherosclerotic vascular diseases [44-46] and various cancers associated with

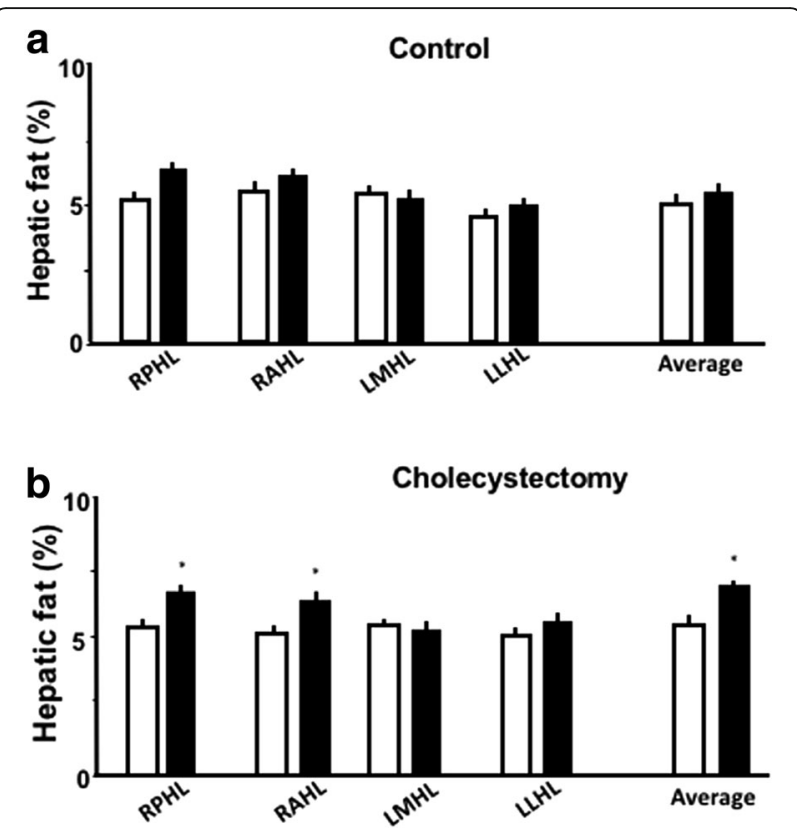

Fig. 2 Effect of XGB on hepatic fat content. Columns represent the mean \pm SE of the percentage of HFC observed at the beginning and after 24 months of follow-up in control (panel a) and cholecystectomized subjects (panel b). White and black columns represent the values obtained at the beginning and end of the study. Four liver segments were analyzed: right posterior hepatic lobe, RPHL; right anterior hepatic lobe, RAHL; left medium hepatic lobe, LMHL; left lower hepatic lobe, $\mathrm{LLHL}$, and mean value of the four lobes. White columns represent values at the beginning of the study and columns with grey dots represent values obtained at the end of the study. ${ }^{*} P<0.03$

obesity [47]. Moreover, NAFLD has become the most prevalent liver condition worldwide and has intrinsic links with IR - MS and a number of associated disease conditions, including cardiovascular diseases [9].

The mechanisms underlying the observed metabolic effects of XGB in the present study remain to be clarified. The GB could theoretically regulate whole body IR/ sensitivity by direct mechanisms, through signaling factors secreted by its mucosa, or indirectly by regulating the flux mass of BAs through the enterohepatic and systemic circulation during the fast-feeding cycles. One of the GB-derived factor that play a role in this setting could be FGF19. This ileal hormone regulates BA synthesis and GB filling and is highly expressed in GB mucosa and secreted into bile [4]. FGF19 has direct systemic metabolic effects on lipid and carbohydrate metabolism [48, 49]. Of note, serum FGF19 levels decrease after XGB [50] and have been found decreased in patients with NAFLD $[51,52]$. Thus, it could be hypothesized that dysregulation of FGF 19 after XGB may in part mediate the metabolic consequences of XGB observed in this study.

With regard to XGB-induced changes in BA physiology, it is generally accepted that XGB determines a decrease in 
the size of the BA pool [22] and increases the enterohepatic recirculation rates of $\mathrm{BA}$ in the fasting state $[53,54]$; the $\mathrm{BA}$ pool recycles at least twice as often as normal after XGB [55]. BA are recognized as relevant signaling molecules [34] that may be critically involved in NAFLD development through their hepatic and extrahepatic effects regulating lipid and carbohydrate metabolic pathways, as well as energy homeostasis [56]. On these grounds, XGB may theoretically determine elevated exposure of both cell surface and nuclear receptors to BAs, leading to pathological effects on triglycerides and glucose homeostasis [22, 23, 33-35].

In our view, three major conclusions can be drawn from this study. The first relates to the observation that XGB favors lipid accumulation in the liver 24 months after surgery. We obtained these results using validated highly sensitive MRI methods [38, 39] that allowed us to evaluate the statistical significance of small changes in the fat fraction of individual liver segments. In fact, although the actual magnitude of the increase in HFC after XGB was small, it is remarkable that these changes occurred in a relatively short time period and reached statistical significance. This result is consistent with the increased prevalence of NAFLD in patients that have underwent XGB reported in two large retrospective population-based studies in North American [25] and Asian populations [26]. Furthermore, a study based on the US National Health and Nutrition Examination Survey (NHANES) showed that XGB, but not GSD, was associated to cirrhosis and elevated serum liver enzymes [57]. Secondly, in our best knowledge, this is the first prospective study showing that GB ablation associates with increased serum insulin levels and HOMA-IR index in humans. These findings are consistent with a number of retrospective cross-sectional epidemiological analyses showing that cholecystectomized patients have increased risks of MS [27], arteriosclerotic vascular diseases [58] and NAFLD $[25,26]$. Our third conclusion is that the observed increase in HFC and HOMA- ${ }_{\text {IR }}$ index 24 months after XGB supports the hypothesis that NAFLD and IR could develop after XGD due to the recently discovered metabolic roles of GB [22]. In a previous mouse study, we found that XGB increases serum and hepatic triglyceride concentrations along with higher VLDL and apoB production [28]. Although not dynamic measurements of insulin sensitivity/resistance are available for those experiments, the metabolic changes observed are suggestive of hepatic IR $[45,46]$. In addition, the elevated levels of apoB, 24 months after XGB is also suggestive of systemic and hepatic IR, since insulin increases the secretion and decreases the clearance of apoB [59].

Based on our current results and the commented experimental and epidemiological evidence, it is theoretically conceivable that a primary altered GB function, even in the absence of GSD, could induce not only gallstone formation, but also potentiate systemic negative metabolic changes. In fact, diabetic patients and individuals with IR with no evidence of gallstones, have abnormal GB motility $[60,61]$, possibly changing their BA kinetics and exposing enterohepatic and peripheral tissues to changes in BA metabolic effects.

\section{Conclusions}

Our results are consistent with previous retrospective epidemiological surveys showing that XGB, but not GBD appears associated as a risk factor of metabolic syndromeassociated complications, particularly to NAFLD. Although this study was performed in a relatively small number of non-obese individuals, it is plausible that XGB could further increase the risk of IR and associated disease conditions in individuals with elevated basal metabolic risk, including obesity and diabetes. Our findings stress the necessity to prevent GSD and perform longer and larger prospective studies to more precisely disclose the metabolic consequences of GB ablation.

\section{Abbreviations}

ALT: Alanine aminotransferase; Apo B: Apolipoprotein B; AST: Aspartate aminotransferase; BA: Bile acid; BMl: Body mass index; FF: Fat fraction; FGF19: Fibroblast growth factor 19; GSD: Gallstone disease; HDL: High density lipoprotein; HFC: Hepatic fat content; HOMA-IR: Homeostasis model assessment index; IDEAL: Iterative decomposition of water and fat with echo asymmetry and least squares estimation; LDL: Low density lipoprotein; LLHL: Left lower hepatic lobe; LMHL: Left medium hepatic lobe; MRI: Magnetic resonance imaging; ms: Milliseconds; NAFLD: Non-alcoholic fatty liver disease; NASH: Nonalcoholic steatohepatitis; RAHL: Right anterior hepatic lobe; ROI: Region of interest; RPHL: Right posterior hepatic lobe; VLDL: Very low-density lipoprotein; $X G B$ : Cholecystectomy

\section{Acknowledgements \\ Authors wish to thank Bogomila Batic and Ludwig Amigo for excellent technical assistance.}

\section{Availability of data and material}

The datasets used and analyzed during the current study are available from the corresponding author on reasonable request.

\section{Funding}

This study was supported by the following grants from the Fondo Nacional Científico y Tecnológico (FONDECYT): 1130146 to FN, 11150329 to N.Q., 1141036 to S.U., 1141134 to VC and 1150327 to MA), and by a grant from the Comisión Nacional de Investigación Científica y Tecnológica (CONICYT) (PIA/Basal PFB12/2007, CARE Chile UC to M.A.), and Conicyt Fondef/IDeA, ID15I10284 to SU.

\section{Authors' contributions \\ VC, MA and FN designed the research, performed the statistical analysis; NQ recruited the patients and collected the data; SU performed NMR images and calculated hepatic fat content; VC, NQ, SU, MA, FN analyzed the data; $\mathrm{MA}$ and FN wrote the paper. All authors approved this final version of the manuscript.}

\section{Ethics approval and consent to participate}

The study was reviewed and approved by the Pontificia Universidad Católica de Chile Review Board. All study participants provided informed written consent prior to study enrollment.

\section{Consent for Publication}

In submitting this article to LIPIDS IN HEALTH AND DISEASE published by BioMed Central I certify that;

1. I am authorized by my co-authors to enter into these arrangements.

2. I warrant, on behalf of myself and my co-authors, that: 
- he article is original, has not been formally published in any other peerreviewed journal, is not under consideration by any other journal and does not infringe any existing copyright or any other third party rights; - I am/we are the sole author(s) of the article and have full authority to enter into this agreement and in granting rights to BioMed Central are not in breach of any other obligation; the article contains nothing that is unlawful, libellous, or which would, if published, constitute a breach of contract or of confidence or of commitment given to secrecy; I/we have taken due care to ensure the integrity of the article. To my/our and currently accepted scientific - knowledge all statements contained in it purporting to be facts are true and any formula or instruction contained in the article will not, if followed accurately, cause any injury, illness or damage to the user.

3. I, and all co-authors, agree that the article, if editorially accepted for publication, shall be licensed under the Creative Commons Attribution License 4.0. In line with BioMed Central's Open Data Policy, data included in the article shall be made available under the Creative Commons 1.0 Public Domain Dedication waiver, unless otherwise stated. If the law requires that the article be published in the public domain, I/we will notify BioMed Central at the time of submission, and in such cases not only the data but also the article shall be released under the Creative Commons 1.0 Public Domain Dedication waiver. For the avoidance of doubt it is stated that sections 1 and 2 of this license agreement shall apply and prevail regardless of whether the article is published under Creative Commons Attribution License 4.0 or the Creative Commons 1.0 Public Domain Dedication waiver.

\section{Competing interests}

The authors declare that they have no competing interests.

\section{Publisher's Note}

Springer Nature remains neutral with regard to jurisdictional claims in published maps and institutional affiliations.

\section{Author details}

'Departamento de Gastroenterología, Facultad de Medicina, Pontificia Universidad Católica de Chile, 6513677 Santiago, Chile. ²Departamento de Nutrición, Facultad de Medicina, Pontificia Universidad Católica de Chile, 6513677 Santiago, Chile. ${ }^{3}$ Departamento de Cirugía Digestiva, Facultad de Medicina, Pontificia Universidad Católica de Chile, 6513677 Santiago, Chile. ${ }^{4}$ División de Imágenes, Laboratorios y Patologías, Departamento de Radiología y Centro de Imágenes Biomédicas, Facultad de Medicina, Pontificia Universidad Católica de Chile, 6513677 Santiago, Chile. ${ }^{5}$ Centro de Envejecimiento y Regeneración (CARE), Departamento de Biología Celular y Molecular, Facultad de Ciencias Biológicas, Pontificia Universidad Católica de Chile, Santiago, Chile.

Received: 19 April 2017 Accepted: 18 June 2017

Published online: 30 June 2017

\section{References}

1. Bellentani S. The epidemiology of non-alcoholic fatty liver disease. Liver Int. 2017;37(Suppl 1):81-4. PubMed

2. Younossi ZM, Koenig AB, Abdelatif D, Fazel Y, Henry L, Wymer M. Global epidemiology of nonalcoholic fatty liver disease-Meta-analytic assessment of prevalence, incidence, and outcomes. Hepatology. 2016;64(1):73-84. PubMed

3. Harris R, Harman DJ, Card TR, Aithal GP, Guha IN. Prevalence of clinically significant liver disease within the general population, as defined by noninvasive markers of liver fibrosis: a systematic review. Lancet Gastroenterology Hepatology. 2017;2(4):288-97. PubMed

4. Saab S, Manne V, Nieto J, Schwimmer JB, Chalasani NP. Nonalcoholic Fatty Liver Disease in Latinos. Clin Gastroenterol Hepatol. 2016;14(1):5-12. quiz e9-0. PubMed

5. Byrne CD, Targher G. NAFLD: a multisystem disease. J Hepatol. 2015;62(1 Suppl):S47-64. PubMed

6. Dietrich P, Hellerbrand C. Non-alcoholic fatty liver disease, obesity and the metabolic syndrome. Best Pract Res Clin Gastroenterol. 2014;28(4): 637-53. PubMed

7. Ahmed $\mathrm{MH}$, Ali A. Nonalcoholic fatty liver disease and cholesterol gallstones: which comes first? Scand J Gastroenterol. 2014;49(5):521-7. PubMed

8. Grundy SM. Metabolic syndrome pandemic. Arterioscler Thromb Vasc Biol. 2008;28(4):629-36. PubMed
9. Yki-Jarvinen $\mathrm{H}$. Non-alcoholic fatty liver disease as a cause and a consequence of metabolic syndrome. Lancet Diabetes Endocrinol. 2014; 2(11):901-10. PubMed

10. Almeda-Valdes P, Aguilar-Olivos N, Uribe M, Mendez-Sanchez N. Common features of the metabolic syndrome and nonalcoholic fatty liver disease. Rev Recent Clin Trials. 2014;9(3):148-58. PubMed

11. Duseja A, Singh SP, Saraswat VA, Acharya SK, Chawla YK, Chowdhury S, et al Non-alcoholic Fatty Liver Disease and Metabolic Syndrome-Position Paper of the Indian National Association for the Study of the Liver, Endocrine Society of India, Indian College of Cardiology and Indian Society of Gastroenterology. J Clinical Experimental Hepatology. 2015;5(1):51-68. PubMed Pubmed Central PMCID: 4415196

12. Lonardo A, Ballestri S, Marchesini G, Angulo P, Loria P. Nonalcoholic fatty liver disease: a precursor of the metabolic syndrome. Dig Liver Dis. 2015; 47(3):181-90. doi:10.1016/j.dld.2014.09.020. PubMed

13. Larrain S, Rinella ME. A myriad of pathways to NASH. Clin. Liver Dis. 2012; 16(3):525-48. PubMed

14. Goh GB, McCullough AJ. Natural History of Nonalcoholic Fatty Liver Disease. Dig Dis Sci. 2016;61(5):1226-33. PubMed

15. Italian Association for the Study of the L. AISF position paper on nonalcoholic fatty liver disease (NAFLD): Updates and future directions. Dig Liver Dis. 2017:49(5):471-83. PubMed

16. Kawano Y, Cohen DE. Mechanisms of hepatic triglyceride accumulation in non-alcoholic fatty liver disease. J Gastroenterol. 2013;48(4):434-41. PubMed Pubmed Central PMCID: 3633701

17. Birkenfeld AL, Shulman Gl. Nonalcoholic fatty liver disease, hepatic insulin resistance, and type 2 diabetes. Hepatology. 2014;59(2):713-23. PubMed Pubmed Central PMCID: 3946772

18. Jelenik T, Kaul K, Sequaris G, Flogel U, Phielix E, Kotzka J, et al. Mechanisms of Insulin Resistance in Primary and Secondary Non-Alcoholic Fatty Liver. Diabetes. 2017; PubMed

19. EASL. Clinical Practice Guidelines on the prevention, diagnosis and treatment of gallstones. J Hepatol. 2016;65(1):146-81. PubMed Epub 2016/04/18. eng

20. Csikesz NG, Singla A, Murphy MM, Tseng JF, Shah SA. Surgeon volume metrics in laparoscopic cholecystectomy. Dig Dis Sci. 2010;55(8):2398-405. PubMed

21. Russo MW, Wei JT, Thiny MT, Gangarosa LM, Brown A, Ringel Y, et al. Digestive and liver diseases statistics, 2004. Gastroenterology. 2004;126(5): 1448-53. PubMed Epub 2004/05/08. eng

22. Housset C, Chretien Y, Debray D, Chignard N. Functions of the Gallbladder. Comprehensive Physiology. 2016;6(3):1549-77. PubMed Epub 2016/06/28. eng

23. Zanlungo S, Rigotti A, Miquel JF, Nervi F. Abnormalities of lipid metabolism, gallstone disease and gallbladder function. Clinical Lipidology. 2011;6:315-25.

24. Nervi F, Arrese M. Cholecystectomy and NAFLD: does gallbladder removal have metabolic consequences? Am J Gastroenterol. 2013;108(6):959-61. PubMed Epub 2013/06/06. eng

25. Ruhl CE, Everhart JE. Relationship of non-alcoholic fatty liver disease with cholecystectomy in the US population. Am J Gastroenterol. 2013;108(6):9528. PubMed Epub 2013/04/03. eng

26. Kwak MS, Kim D, Chung GE, Kim W, Kim YJ, Yoon JH. Cholecystectomy is independently associated with nonalcoholic fatty liver disease in an Asian population. World J Gastroenterol. 2015;21(20):6287-95. PubMed Pubmed Central PMCID: 4445106. Epub 2015/06/03. eng

27. Shen C, Wu X, Xu C, Yu C, Chen P, Li Y. Association of cholecystectomy with metabolic syndrome in a Chinese population. PLoS One. 2014;9(2):e88189. PubMed Pubmed Central PMCID: 3914934

28. Amigo L, Husche C, Zanlungo S, Lutjohann D, Arrese M, Miquel JF, et al. Cholecystectomy increases hepatic triglyceride content and very-lowdensity lipoproteins production in mice. Liver Int. 2011;31(1):52-64. PubMed Epub 2010/11/03. eng

29. Cortes V, Amigo L, Zanlungo S, Galgani J, Robledo F, Arrese M, et al. Metabolic effects of cholecystectomy: gallbladder ablation increases basal metabolic rate through G-protein coupled bile acid receptor Gpbar1dependent mechanisms in mice. PLoS One. 2015;10(3):e0118478. PubMed Pubmed Central PMCID: 4349594. Epub 2015/03/05. eng

30. Juvonen T, Kervinen K, Kairaluoma MI, Kesaniemi YA. Effect of cholecystectomy on plasma lipid and lipoprotein levels. HepatoGastroenterology. 1995;42(4):377-82. PubMed Epub 1995/07/01. eng

31. Sonne DP, Hare KJ, Martens P, Rehfeld JF, Holst JJ, Vilsboll T, et al. Postprandial gut hormone responses and glucose metabolism in cholecystectomized patients. Am J Physiol Gastrointest Liver Physiol. 2013; 304(4):G413-9. PubMed Epub 2013/01/01. eng 
32. Ali RB, Cahill RA, Watson RG. Weight gain after laparoscopic cholecystectomy. Ir J Med Sci. 2004;173(1):9-12. PubMed Epub 2005/ 03/01. eng

33. Schonewille M, de Boer JF, Groen AK. Bile salts in control of lipid metabolism. Curr Opin Lipidol. 2016;27(3):295-301. PubMed Epub 2016/ 04/01. eng

34. Chiang JY. Bile acid metabolism and signaling. Comprehensive Physiology. 2013;3(3):1191-212. PubMed Pubmed Central PMCID: 4422175. Epub 2013/ 07/31. eng

35. Arab JP, Karpen SJ, Dawson PA, Arrese M, Trauner M. Bile acids and nonalcoholic fatty liver disease: Molecular insights and therapeutic perspectives. Hepatology. 2017;65(1):350-62. PubMed Pubmed Central PMCID: 5191969

36. Gariani K, Philippe J, Jornayvaz FR. Non-alcoholic fatty liver disease and insulin resistance: from bench to bedside. Diabetes Metab. 2013;39(1):16-26. PubMed Epub 2012/12/26. eng

37. Matthews DR, Hosker JP, Rudenski AS, Naylor BA, Treacher DF, Turner RC. Homeostasis model assessment: insulin resistance and beta-cell function from fasting plasma glucose and insulin concentrations in man Diabetologia. 1985;28(7):412-9. PubMed Epub 1985/07/01. eng

38. Idilman IS, Aniktar H, Idilman R, Kabacam G, Savas B, Elhan A, et al. Hepatic steatosis: quantification by proton density fat fraction with MR imaging versus liver biopsy. Radiology. 2013;267(3):767-75. PubMed Epub 2013/02/06. eng

39. Tang A, Tan J, Sun M, Hamilton G, Bydder M, Wolfson T, et al. Nonalcoholic fatty liver disease: MR imaging of liver proton density fat fraction to assess hepatic steatosis. Radiology. 2013;267(2):422-31. PubMed Pubmed Central PMCID: 3632805. Epub 2013/02/06. eng

40. Acosta AM, Escalona M, Maiz A, Pollak F, Leighton F. Determination of the insulin resistance index by the Homeostasis Model Assessment in a population of Metropolitan Region in Chile. Revista medica de Chile. 2002 130(11):1227-31. PubMed Epub 2003/02/18. Determinacion del indice de resistencia insulinica mediante HOMA en una poblacion de la region metropolitana de Chile. spa.

41. Reeder SB, Pineda AR, Wen Z, Shimakawa A, Yu H, Brittain JH, et al. Iterative decomposition of water and fat with echo asymmetry and least-squares estimation (IDEAL): application with fast spin-echo imaging. Magn Reson Med. 2005:54(3):636-44. PubMed Epub 2005/08/11. eng

42. Glover GH. Multipoint Dixon technique for water and fat proton and susceptibility imaging. J Magn Reson Imaging. 1991;1(5):521-30. PubMed Epub 1991/09/01. eng

43. Arboleda C, Aguirre-Reyes D, Garcia MP, Tejos C, Munoz L, Miquel JF, et al. Total liver fat quantification using three-dimensional respiratory selfnavigated MRI sequence. Magn Reson Med. 2016;76(5):1400-9. PubMed

44. Fotbolcu H, Zorlu E. Nonalcoholic fatty liver disease as a multi-systemic disease. World J Gastroenterol. 2016:22(16):4079-90. PubMed Pubmed Central PMCID: 4837427. Epub 2016/04/29. eng

45. Abbasi F, Brown BW Jr, Lamendola C, McLaughlin T, Reaven GM. Relationship between obesity, insulin resistance, and coronary heart disease risk. J Am Coll Cardiol. 2002:40(5):937-43. PubMed Epub 2002/09/13. eng

46. Patel TP, Rawal K, Bagchi AK, Akolkar G, Bernardes N, Dias Dda S, et al. Insulin resistance: an additional risk factor in the pathogenesis of cardiovascular disease in type 2 diabetes. Heart Fail Rev. 2016;21(1):11-23. PubMed Epub 2015/11/07. eng

47. lyengar NM, Hudis CA, Dannenberg AJ. Obesity and cancer: local and systemic mechanisms. Annu Rev Med. 2015;66:297-309. PubMed Epub 2015/01/15. eng

48. Jahn D, Rau M, Hermanns HM, Geier A. Mechanisms of enterohepatic fibroblast growth factor 15/19 signaling in health and disease. Cytokine Growth Factor Rev. 2015;26(6):625-35. PubMed Epub 2015/08/08. eng

49. Nies VJ, Sancar G, Liu W, van Zutphen T, Struik D, Yu RT, et al. Fibroblast Growth Factor Signaling in Metabolic Regulation. Front Endocrinol. 2015;6: 193. PubMed Pubmed Central PMCID: 4718082. Epub 2016/02/03. eng

50. Barrera F, Azocar L, Molina H, Schalper KA, Ocares M, Liberona J, et al. Effect of cholecystectomy on bile acid synthesis and circulating levels of fibroblast growth factor 19. Ann Hepatol. 2015;14(5):710-21. PubMed Epub 2015/08/11. eng

51. Wojcik M, Janus D, Dolezal-Oltarzewska K, Kalicka-Kasperczyk A, Poplawska K, Drozdz D, et al. A decrease in fasting FGF19 levels is associated with the development of non-alcoholic fatty liver disease in obese adolescents. J Pediatr Endocrinol Metab. 2012;25(11-12):1089-93. PubMed Epub 2013/01/19. eng

52. Eren F, Kurt R, Ermis F, Atug O, Imeryuz N, Yilmaz Y. Preliminary evidence of a reduced serum level of fibroblast growth factor 19 in patients with biopsy-proven nonalcoholic fatty liver disease. Clin Biochem. 2012;45(9): 655-8. PubMed Epub 2012/04/03. eng
53. Shaffer EA, Small DM. Biliary lipid secretion in cholesterol gallstone disease. The effect of cholecystectomy and obesity. J Clin Invest. 59(5):1977, 828-40. PubMed Pubmed Central PMCID: 372291. Epub 1977/05/01. eng

54. Roda E, Aldini R, Mazzella G, Roda A, Sama C, Festi D, et al. Enterohepatic circulation of bile acids after cholecystectomy. Gut. 1978;19(7):640-9. PubMed Pubmed Central PMCID: 1412071. Epub 1978/07/01. eng

55. Malagelada JR, Go VL, Summerskill WH, Gamble WS. Bile acid secretion and biliary bile acid composition altered by cholecystectomy. Am J Dig Dis. 1973;18(6):455-9. PubMed Epub 1973/06/01. eng

56. Arab JP, Karpen SJ, Dawson PA, Arrese M, Trauner M. Bile acids \& nonalcoholic fatty liver disease: Molecular insights and therapeutic perspectives. Hepatology. 2017;65(1):350-362.

57. Ioannou GN. Cholelithiasis, cholecystectomy, and liver disease. Am J Gastroenterol. 2010;105(6):1364-73. PubMed Epub 2010/01/14. eng

58. Mendez-Sanchez N, Bahena-Aponte J, Chavez-Tapia NC, Motola-Kuba D, Sanchez-Lara K, Ponciano-Radriguez G, et al. Strong association between gallstones and cardiovascular disease. Am J Gastroenterol. 2005;100(4):82730. PubMed Epub 2005/03/24. eng

59. Haas ME, Attie AD, Biddinger SB. The regulation of ApoB metabolism by insulin. Trends Endocrinol Metab. 2013:24(8):391-7. PubMed Pubmed Central PMCID: 3810413. Epub 2013/06/01. eng

60. Arshad F, Laway BA, Rather TA, Kuchay MS, Khan SH. Impaired gallbladder motility in adults with newly detected type 2 diabetes and lack of reversibility after achieving euglycemia. Can J Diabetes. 2015;39(2):101-4. PubMed Epub 2014/12/03. eng

61. Nakeeb A, Comuzzie AG, Al-Azzawi H, Sonnenberg GE, Kissebah AH, Pitt HA Insulin resistance causes human gallbladder dysmotility. J Gastrointest Surg. 2006;10(7):940-8. discussion 8-9. PubMed Epub 2006/07/18. eng

\section{Submit your next manuscript to BioMed Central and we will help you at every step:}

- We accept pre-submission inquiries

- Our selector tool helps you to find the most relevant journal

- We provide round the clock customer support

- Convenient online submission

- Thorough peer review

- Inclusion in PubMed and all major indexing services

- Maximum visibility for your research

Submit your manuscript at www biomedcentral.com/submit
C Biomed Central 